\title{
Konut Talebine Göre Benzer Özellik Gösteren Türkiye İllerinin Panel Veri Kümeleme Analizi ile Belirlenmesi
}

\begin{abstract}
Özlem AKAY ${ }^{1}$
Cahit ÇELIK ${ }^{2}$

Gülsen KIRAL ${ }^{3}$

ÖZ: Bu çalışmanın amacı Türkiye'nin konut talebinde benzer özellik gösteren illerini uygun kümeleme yöntemi belirlemektir. Bu amaç doğrultusunda, 2008-2015 yillarl arasında Türkiye illerinin konut talebi ve konut talebini etkileyen ekonomik faktörleri ele alınarak panel veri seti oluşturulmuştur. Ele alınan panel veri setine, Öklid, Gower ve K-prototip uzaklıklarl kullanılarak toplamsal hiyerarşik kümeleme yöntemleri (Average, Complete, Ward, Single ve WPGMA) uygulanmıştır. Kümeleme yöntemlerinin Cophenetic korelasyon katsayısı hesaplanarak uzaklıklar için uygun kümeleme yöntemleri belirlenmiştir. Belirlenen kümeleme yöntemlerinin küme geçerlilik (Dunn, Silhouette ve Connectivity) indeks değerleri hesaplanmıştır. Indeks değerlerine göre, veri seti için Öklid uzaklı̆̆ kullanılarak yapılan WPGMA kümeleme yönteminin uygun olduğu tespit edilmiştir. WPGMA yönteminin kümeleme sonucuna göre Türkiye'nin konut talebinde benzer özellik gösteren illeri belirlenmiştir.
\end{abstract}

Anahtar Kelimeler: Konut Talebi, Ekonomik Faktörler, Panel Veri, Kümeleme

JEL Kodu: C18, C23, C38

\section{Determine Provinces of Turkey that Show Similar Characteristics for Housing Demand by Using Clustering of Panel Data}

\begin{abstract}
The main aim of this study is to_determine provinces of Turkey_that_show similar characteristics in accordance with housing demand by using appropriate clustering method. For this purpose, panel data set has been created between the years 2008-2015 the housing demand of Turkey's province and economic factors affecting housing demand. Agglomerative hierarchical clustering methods (Average, Complete, Ward, Single and WPGMA) were applied to the panel data set by using Euclid, Gowerand K-prototype distances. Cophenetic correlation coefficient of the clustering methods was calculated and appropriate clustering methods were determined for the distances. The cluster validity (Dunn, Silhouette and Connectivity) index values of the determined clustering methods were calculated. According to the index values, it was determined that the WPGMA clustering method using Euclidean distance is suitable for the data set. Considering the results of WPGMA clustering methods, provinces of Turkey that show similar characteristics were determined for housing demand.
\end{abstract}

Keywords: Housing Demand, Economic Factors, Panel Data, Cluster Analysis JEL Codes: C18, C23, C38

Geliş Tarihi / Received: 24/06/2019

Kabul Tarihi / Accepted: 24/07/2019

\footnotetext{
${ }^{1}$ Arş. Gör. Dr. Çukurova Üniversitesi, İstatistik Bölümü, oakay@cu.edu.tr, orcid.org/0000-00029539-7252.

2 Dr. Çukurova Üniversitesi Ekonometri Bölümü, cahit.celik@ outlook.com, orcid.org/0000- 00034813-940X.

${ }^{3}$ Doç. Dr. Çukurova Üniversitesi, Ekonometri Bölümü, gkiral@cu.edu.tr, orcid.org/0000-00020541-0178.
} 


\section{Giriş}

Türk konut sektörü son on beş yıllık süreçte çok hızlı bir gelişim göstermiştir. İnşaat sektörünün makroekonomi açısından önemi çarpan etkisinden kaynaklanmaktadır. Bu nedenle inşaat sektörü 250 alt sektörü harekete geçirerek gerek büyüme gerekse istihdam üzerinde etki yaratmaktadır. Son dönemde Türkiye ekonomisinin lokomotiflerinden biri olmasına ek olarak çimento, demir-çelik, plastik vb. birçok alt sektörü etkilemesi nedeniyle konut sektöründeki gelişmeler yakından takip edilmektedir. Ekonominin genel konjonktürü dünyada olduğu gibi Türkiye'de de inşaat sektörünün performansını doğrudan etkilemektedir. İnşaat sektörü değişkenleri çok dikkatli bir biçimde ve belli bir sürede analiz edilmektedir. Zamanla etkisi daha az olacağı varsayılan değişkenlerin etkisi yüksek olurken, bazı dönemlerde ise tam tersi olabilmektedir. Buna bağlı olarak, konut kredi faizlerinin yükselmesi bir yandan tüketicinin talebini düşürürken diğer yandan üretim maliyetlerini de artırmaktadır. Fakat bazı dönemlerde tüketim ile faiz arasındaki duyarlılık oldukça azalmaktadır. Bourdieu ve Wacquant (1992), konutu bireylerin kendisini rahat hissettiği, alışkanlıklarını geliştirdiği bir yer olarak tanımlamaktadır.

Konut piyasası, tüketiciler ile üreticiler arasında devlet müdahalesine ihtiyaç duyulmadan konut malının değişimine fiyat aracını kullanarak izin veren bir mekanizmadır (Donaldson ve Gerard, 1998: 13). Konut talebindeki eğilimleri görebilmek için konut fiyat endeksi, konut kredileri, faiz oranları, tüketici güven endeksleri, (GSYH) Gayri Safi Yurtiçi Hâsıla, kur, altın fiyatları vb. değişkenler dikkate alınmalıdır. Buna göre 2000'li yılların başından itibaren düşüş eğilimi içerisinde olan enflasyon ve faiz oranları, konut alımlarında banka kredilerini önemli bir finansman aracı haline getirmiştir. Kredili konut alımlarındaki artış ile birlikte kredi koşulları, bireylerin ev alım kararı üzerindeki etkisini arttırmaktadır. 2008 yılından itibaren konut kredisi faiz oranındaki eğilimin, konjonktürel dalgalanmalar göstermekle birlikte, aşağı yönlü olduğu gözlenmektedir. Kredi maliyetlerinin azalması ve uygun makroekonomik koşulların etkisiyle uzayan vadeler, konut kredisine olan talebin artmasına katkıda bulunan faktörler arasındadır. Araştırma evrenini oluşturan panel veri kümeleri TÜİK (Türkiye İstatistik Kurumu)'in 2008-2015 dönemlerinde illere ve yıllara göre konut satış sayıları ve konut satışlarını etkileyen ekonomik değişkenlerin verilerinden oluşmaktadır. Türkiye'de konut talebinde benzer özellik gösteren iller, bu illerde konut satışlarını etkileyen ekonomik faktörler ele alınarak uygun uzaklık ölçüsü ve hiyerarşik kümeleme yöntemi ile belirlenmeye çalışılacaktır. Bu çalışma beş bölümden oluşmaktadır. Çalışmanın birinci bölümünde, konut ve alt sektör bileşenleri açıklanmıştır. Ayrıca Türkiye'de ikamet eden hane halklarının konut talebini ve konut değerini etkileyen ekonomik faktörler açıklanmıştır. İkinci bölümde, araştırma konusunu ile ilgili literatür araştırmasına yer verilmiştir. Üçüncü bölümde, araştırma zamanı ve kapsamına ilişkin karma değişkenli panel veri setinin kümelenmesinde kullanılacak uzaklık ölçümleri ayrıntılı olarak açıklanmıştır. Dördüncü bölümde ise analiz ve bulgulara yer verilmiştir. Çalışmanın son bölümünü sonuç ve öneriler oluşturmaktadır. 


\section{Literatür}

Konut talebi ile ilgili yapılan araştırmalar son yıllarda önemli bir ilgi alanı haline gelmekte ve konu ile ilgili çalışmaların sayısı gittikçe artmaktadır. Konut talebine ilişkin yapılan çalışmalardan bazıları kronolojik sıra ile özetlenmiştir.

Quigley (1976), iş yeri konumundaki değişikliklerden kaynaklanan konut fiyatlarındaki intrametropolit varyasyonları içeren konut tipi arasında ev seçimi modeli sunmuştur. Uygun varsayımlar altında hane halkının alternatif konut türleri arasından seçim yaparken karşılaştığı fiyatları açıklamıştır. Goodman ve Kawai (1982), bireysel hane halkı verilerine bağlı olarak gelir ve fiyat değişkenlerini ile konut talebini incelemişlerdir. İnsan ve insanlık dışı servetle ilgili araçsal değişkenlerle kalıcı ve geçici gelirleri hesaplamışlardır. Jud ve Frew (1986), emlak komisyoncularının konut piyasası pazarındaki rolünü incelemişlerdir. Komisyoncuların sattıkları evlerde oldukça yüksek fiyatlar elde ettiklerini ve dolaylı olarak komisyon yükünün bir kısmını alıcıya kaydırdığını göstermişlerdir. Emlak komisyoncusu yardımıyla konut piyasasını arayan alıcıların, konut piyasasına bir aracı yardımı olmadan alışveriş yapan alıcılardan daha fazla konut talebinde bulunduğunu öne süren kanıtlar bulmuşlardır. Goodman (1990), talep sistemlerine demografik değişkenlerin dahil edildiği yöntemleri incelemiştir. Ardından, görev seçimi ve talebinin birlikte belirlendiği ve tahmin edildiği konut talebi denklem sistemini araştırmıştır. Green ve Hendershott (1996), yaşın konut talebinde yaşın etkisinin toplam ve kısmi türevlerini hesaplamıştır. Yapının yaşının, eğitim ve gelirin, hane halkının sabit kalitede bir ev için ödeme yapma zorluğu üzerindeki etkisini ölçmek için 1980 nüfus sayımı verilerini kullanmışlardır. Rapaport (1997), üç bileşenden oluşan bir ekonometrik model geliştirmiş ve bu modeli, Tampa, Florida'daki hane halkı örneklerini kullanarak tahmin etmiştir. Topluluk seçiminin dahil edilmesi, talebin fiyat esnekliğini arttırmakta ve beyaz ile kıyaslanabilir beyaz olmayan haneler arasındaki farkı azalmaktadır. Sonuçlar, kalıcı gelir ve vergilerin dahil edilmesine dirençlidir. Ioannides ve Zabel (2003), komşuluk etkili konut talebi modelini tahmin etmiştir. Amerikan Konut Anketi'nin ulusal örneğinin özel özelliklerini ve "doğal” araçlar yaratmalarına izin veren konut piyasalarının özelliklerini kullanmışlardır. Böylece, sosyal etkileşimlerin etkisini belirlemişlerdir. Bajari ve Kahn (2005), konut niteliğine ödeme yapma isteğini iyileştirmek için üç aşamalı, parametrik olmayan bir tahmin yöntemi sunmuşlardır. İlk aşamada parametrik olmayan hedonik ev fiyatı fonksiyonunu tahmin etmişlerdir. İkinci aşamada, fayda maksimizasyonu için birinci derece koşulları kullanarak her bir tüketicinin ürün karakteristikleri için beğeni parametrelerini iyileştirmişlerdir. Son olarak, üçüncü aşamada hane halkı demografisinin fonksiyonu olarak hane halkı beğeni dağılımını tahmin etmişlerdir. Güriş ve Çağlayan (2011), Türkiye'de hem şehir hem de kırsal alanda ev sahibi olma olasılığını etkileyen çeşitli faktörleri incelemişlerdir. Logit, Probit ve Gompit olarak adlandırılan üç farklı ikili bağımlı değişken modelini kullanmışlar ve karşılaştırma yaparak en iyi modeli belirlemişlerdir. Daşkıran (2015), Denizli şehir merkezinde rastgele örneklem alarak 102 ev için anket çalışması yapmıştır. Anket 
sonuçlarından elde edilen verilerle, logaritmik regresyon kullanarak konut fiyatına etkileri incelenmiştir. Bu analizlere göre; evin fiyatı ile evin zemini, asansör, oda ve banyo sayısı, radyatörlü ısıtma sistemi, eğitim ve sağlık kuruluşlarına ve şehir merkezine uzaklığı arasında anlamlı bir ilişki olduğu görülmüştür. Öte yandan evin yaşı, evin yeri (cadde ve sokak) ile toplu taşıma araçlarına uzaklığı arasında bir ilişki bulunamamıştır. Çelik ve Kıral (2018), Türkiye il gruplarının konut satışlarını etkileyen faktörlerine dengeli ve dengesiz panel veri analizi ile kümeleme analiz yöntemlerini uygulamışlar ve elde edilen anlamlı değişkenleri hiyerarşik kümeleme yöntemi ile incelemişlerdir. Ayrıca bu çalışmayı SWOT analizi ile desteklemişlerdir. Çelik ve Kıral (2018),2008-2015 dönemi Türkiye illeri y1llık konut satış sayıları ve konut satışlarını etkileyen faktörleri ele alarak SWOT analizi ve panel veri kümeleme analizi ile incelemişlerdir. Çalışmadan elde edilen bulgulara göre, mevduat faiz oranının, kentleşme oranının, hane halkı otomobil sayısının, ortalama hane halkı gelirinin, konut brüt getiri oranının, Borsa İstanbul 100 endeksinin ve konut kredisi faiz oranının konut talebinde anlamlı olduğunu belirlemişlerdir. Akay ve Yüksel (2018), karma panel veri setine Gower uzaklığ kullanarak toplamsal hiyerarşik kümeleme algoritmaları ve k-prototip algoritması ile kümeleme analizi uygulamışlardır. Akay ve Yüksel (2018), bilgi kaybını önlemek için değişken dönüşümü yapmadan, zaman değişmezi ikili değişken içeren karma değişkenli panel veri setini kümelemede kullanılmak üzere yeni bir uzaklık ölçümü önermişlerdir. Zaman değişmezi içeren karma değişkenli panel veri seti kümelemede, önerilen uzaklık ölçümünün, Gower ve k-prototip uzaklık ölçümlerinden daha iyi sonuç verdiğini göstermişlerdir.

\section{Panel Veri Kümeleme Analizi}

Panel veri aynı birimin zaman içerisinde tekrarlı gözlemlerinden oluşan veri setidir. Panel veri yatay kesit verilerini ve zaman serilerini bir araya getirmektedir. Yatay kesit veriler ile zaman serilerinin birleşmesi sonucu oluşan panel veri hem yatay kesit hem de zaman serilerinin özelliklerini içermektedir. Buna göre daha çok aydınlatıcı veri, daha çok değişkenlik, değişkenler arasında daha az doğrusal bağlantı, daha çok serbestlik derecesi ve daha çok etkinlik sağlamaktadır (Gujarati, 2016: 406). Panel veride önemli konulardan biri verideki farklı birimlerin havuzlanabilirliğidir. Son zamanlardaki bazı çalışmalar farklı gruplardaki birimleri kümeleyerek kısmi havuzlanabilirliği araştırmışlardır (Lu ve Huang, 2011: 2).Çok değişkenli panel veri yapısı üç boyutlu yapıda veya matris formunda gösterilebilir. Panel verilerde kümeleme analizi yapmak için iki boyut taşınarak tek boyuta devredilir. Toplamdaki birim sayısının $N$ olduğunu, her birimin özelliğinin $p$ değişkeni ile gösterildiğini $\left(X_{1}, X_{2}, \ldots, X_{j}, X_{p}\right)$ ve uzunluğun $T$ olduğu varsayılsın. Böylece $X_{i j}(t) t$ zamanındaki $i$. birimin $j$. değişken değeridir. Çok değişkenli panel verilerde kümeleme analizi yapılırken kümeleme sürecinde öncelikli adımlardan biri olan uzaklık ölçümü ve kümeleme algoritması yeniden yapılandırılır. Zaman boyutu eklenen çok değişkenli panel veri için uzaklık fonksiyonu kesit verisi 
uzaklık fonksiyonundan farklıdır. Zaman boyutu eklenen Öklid, Gower ve Kprototip uzaklıkları aşağıdaki gibi tanımlanmıştır.

Zaman boyutu eklenen Öklid uzaklığı zamansal ve uzaysal öklid uzaklığı olarak yeniden adlandırılır (Zheng and Li, 2014: 555). $r$ ve $k$ birimleri arasındaki zamansal ve uzaysal öklid uzaklığı $d_{r k}$ olarak gösterilir ve Eşitlik (1)'deki gibi tanımlanır.

$$
d_{r k}=\left\{\sum_{t=1}^{T} \sum_{j=1}^{p}\left[X_{r j}(t)-X_{k j}(t)\right]^{2}\right\}^{1 / 2}
$$

Karma değişkenli panel veriyi kümeleyebilmek için karma verileri kümelemede kullanılan Gower uzaklığı ve k-prototip uzaklığı karma değişkenli panel veri için düzenlenmiştir.

Karma değişkenli panel veri için Gower benzerlik ölçümü Eşitlik (2)'deki gibi düzenlenir.

$$
S\left(X_{i j}(t), X_{s j}(t)\right)=\frac{\sum_{t=1}^{T} \sum_{j=1}^{p} \delta_{i s j}(t) S_{i s j}(t)}{\sum_{t=1}^{T} \Sigma_{j=1}^{p} \delta_{i s j}(t)}
$$

Burada $S_{i s j}(t), t$ zamanında $j$. özellik için iki birim arasındaki benzerliği gösterir. $\delta_{i s j}(t)$, iki birim ölçümünde kayıp veri olup olmamasına dayalı olarak 0-1 katsayılıdır. Kesikli değişken için (ikili değişken içeren) benzerlik;

$$
S_{i s j}(t)= \begin{cases}1 & X_{i j}(t)=X_{s j}(t) \\ 0 & X_{i j}(t) \neq X_{s j}(t)\end{cases}
$$

şeklindedir. Nümerik değişkenler için $S_{i s j}$,

$$
S_{i s j}(t)=1-\frac{\left|X_{i j}(t)-X_{s j}(t)\right|}{R_{j}(t)}
$$

olarak ifade edilir. Burada $R_{j}(t)$ tüm birimlerin $t$ zamanında $j$. değişkenin aralığıdır ve $R_{j}(t)=\max _{j}(t)-\min _{j}(t)$ olarak hesaplanır. $D\left(X_{i j}(t), X_{s j}(t)\right)=1-$ $S\left(X_{i j}(t), X_{s j}(t)\right)$ basit eşitliği kullanılarak uzaklık ölçüsü elde edilebilir.

Karma değişkenli panel veri için k-prototip uzaklığı Eşitlik (5)’teki gibi düzenlenir.

$$
d(i, s)=\sum_{i, s \in A_{r}} \sum_{t=1}^{T} \sum_{p=1}^{P}\left\{\frac{X_{i j}(t)-X_{s j}(t)}{\max \left(X_{j}(t)\right)-\min \left(X_{j}(t)\right)}\right\}^{2}+\gamma \sum_{i, s \in A_{c}} \sum_{t=1}^{T} \sum_{j=p+1}^{m} \delta\left(X_{i j}(t), X_{s j}(t)\right)
$$

Eşitliğin ilk terimi nümerik değişkenler için zamansal ve uzaysal öklid uzaklığının karesidir ve tüm nümerik değişkenler $[0,1]$ aralığında normalleştirilir. Eşitliğin ikinci terimi ikili değişkenler için basit eşleştirme uzaklık ölçümüdür ve $[0.5,1.4]$ aralığında değer alan $\gamma$ değeri ile ağırlıklandırılır.

Elde edilen uzaklıklar kullanılarak toplamsal hiyerarşik kümeleme yöntemleri olan tek bağlantı, tam bağlantı, ortalama, ağırlıklı ortalama ve Ward yöntemleri ile birimler kümelenir. 


\section{Ampirik Analiz}

Bu çalışmada, Türkiye'nin konut talebinde benzer özellik gösteren illerini belirlemek amaciyla 2008-2015 yılları arasında Türkiye illerinin konut talebi ve konut talebini belirleyen ekonomik faktörleri ele alınarak panel veri seti oluşturulmuştur. Ekonomik faktörler, Konut fiyat endeksi, Ağırlıklı ortalama faiz oranları, Gayri safi yurt içi hâsıla, Tüketici fiyatları endeksi, Üretici fiyatı endeksi, Tüketici güven endeksi, Ortalama hane halkı geliri, Hane halkı tasarruf oranı ve Konut brüt getiri oranı olarak belirlenmiş ve Tablo 1'de ayrıntılı olarak açıklanmıştır.

İncelenen panel veri setine, Öklid, Gower ve K-prototip uzaklıkları uygulanarak toplamsal hiyerarşik kümeleme yöntemleri (Average, Complete, Ward, Single ve WPGMA) ile kümeleme analizi yapılmıştır. Elde edilen kümelerin uygunluğunun tespit edilmesinde kullanılan temel yaklaşımlardan biri Cophenetic korelasyon katsayısının (cophenetic correlation coefficient) belirlenmesidir. Cophenetic korelasyon katsayısı (CCC), X veri kümesi için hesaplanan benzerlik matrisi $\mathrm{P}=\left\{\mathrm{p}_{\mathrm{ij}}\right\}$ ile hiyerarşik kümeleme yöntemine göre elde edilen ağaç diyagramında veri gözlem çiftlerinin ilk defa aynı kümede gruplandığı yakınlık seviyeleri $\mathrm{q}_{\mathrm{ij}}$ değerlerinden oluşan Cophenetic matrisi $\mathrm{Q}=\{\mathrm{qij}\}$ arasındaki benzerliğin bir ölçüsüdür veCCC, [-1,1] arasında değer alır. CCC değerinin 1 olması verideki hiyerarşi yapıdan elde edilen $\mathrm{P}=\{$ pij $\}$ ve $\mathrm{Q}=\{$ qij $\}$ arasında yüksek derecede benzerlik olduğunu gösterir. Bu nedenle, kullanılan uzaklık ölçümlerine göre uygun kümeleme yöntemini belirlemek amacıyla, üç uzaklık kullanılarak yapılan toplamsal hiyerarşik yöntemlerin Cophenetic korelasyon değerleri elde edilmiş ve Tablo 2'de verilmiştir. 
Tablo 1:Konut Talebinde Panel Ekonomik Faktörler ve Tanımları

\begin{tabular}{|c|c|}
\hline $\begin{array}{l}\text { Panel } \\
\text { Değişkenleri }\end{array}$ & Değişkenlerin Tanımı \\
\hline KT & $\begin{array}{l}\text { Konut Talebi: TÜIK'in (2008-2015) yılları arasındaki konut talep } \\
\text { istatistikleri. }\end{array}$ \\
\hline KFE & $\begin{array}{l}\text { Konut Fiyat Endeksi: Türkiye konut sektöründeki fiyat değişikliklerinin } \\
\text { takip edilmesine yönelik, ülke genelini kapsayan bir endekstir. }\end{array}$ \\
\hline AOFO & $\begin{array}{l}\text { Bankacılık ve Finansal Kuruluşlar Genel Müdürlüğü (BFKGM)' nün } \\
\text { açıklamasına göre, Ağırlıklı Ortalama Faiz Oranlarında; Resmi } \\
\text { Mevduat, Tasarruf Mevduatı, Bankalar arası Mevduat, Ticari Mevduat } \\
\text { ve Diğer Mevduat Faiz Oranları dâhildir. }\end{array}$ \\
\hline GSYH & $\begin{array}{l}\text { Gayri Safi Yurtiçi Hâsıla: GSMH (Gayri Safi Milli Hâsıla)'dan farklı } \\
\text { olarak, bir ülke sınırları içerisinde belli bir zaman içinde, üretilen tüm } \\
\text { nihai mal ve hizmetlerin para birimi cinsinden değeridir. }\end{array}$ \\
\hline TÜFE & $\begin{array}{l}\text { Tüketici Fiyatları Endeksi: Tipik bir tüketicinin satın aldığı belirli bir } \\
\text { ürün ve hizmet grubunun fiyatlarındaki ortalama değişimleri gösteren } \\
\text { bir ölçüttür. Yıllık enflasyon değerlerindeki değişimi ölçmek için } \\
\text { kullanılır. TÜFE, istatistik bilimindeki indeks sayılar ile hesaplanır. }\end{array}$ \\
\hline ÜFE & $\begin{array}{l}\text { Üretici Fiyatı Endeksi: Belirli bir referans döneminde ülke } \\
\text { ekonomisinde üretimi yapılan ve yurtiçine satı̧sa konu olan ürünlerin, } \\
\text { üretici fiyatlarını zaman içinde karşılaştırarak fiyat değişikliklerini ölçen } \\
\text { fiyat endeksidir. }\end{array}$ \\
\hline TGE & $\begin{array}{l}\text { Tüketici Güven Endeksi: Aylık olarak hazırlanan, Türkiye genelinde } \\
\text { tesadüfî seçilen haneleri temsil eden bireyler ile yapıllan tüketici eğilim } \\
\text { anketlerine göre bireylerin mevcut ekonomik koşullara ilişkin fikirleri, } \\
\text { mali durumu ve gelecekteki beklentileri belirlenerek hesaplanmaktadır. }\end{array}$ \\
\hline OHG & $\begin{array}{l}\text { Ortalama Hane halk1 Geliri: \%20'lik gruplara göre ortalama hane halk1 } \\
\text { y1llık geliri. }\end{array}$ \\
\hline HTO & $\begin{array}{l}\text { Hane halkı Tasarruf Oranı: Yıllık her bir hane halkının birikimlerinin } \\
\text { oranı. }\end{array}$ \\
\hline KBGO & $\begin{array}{l}\text { Konut Brüt Getiri Oranı: Bir konutun kira ve satış fiyatı yardımıyla elde } \\
\text { edilen orandır. Bu değerler konuttan elde edilen yıllık brüt getiriyi } \\
\text { göstermektedir. }\end{array}$ \\
\hline
\end{tabular}

Kaynak: TÜİK (2008-2015), Konut talep istatistiği ve konut talebini belirleyen faktörler 
Tablo 2'de görüldüğü gibi Öklid ve Gower uzaklıkları kullanılarak yapılan toplamsal hiyerarşik kümele yöntemlerinden uygun kümeleme yöntemi WPGMA (sırasıyla Cophenetic korelasyon değerleri, 0.9825 ve 0.9774 ), K-prototip uzaklığı kullanılarak yapılan toplamsal hiyerarşik kümele yöntemlerinden uygun kümeleme yöntemi ise Ortalama bağlantı yöntemi (0.8286) olarak belirlenmiştir.

Tablo 2:Cophenetic Korelasyon Değerleri

\begin{tabular}{|c|c|c|c|}
\hline & \multicolumn{3}{|c|}{ Cophenetic } \\
\hline Uzaklık Yöntemleri & Öklid & Gower & K-prototip $(\gamma=1)$ \\
\hline Average & 0.9815 & 0.1749 & $\mathbf{0 . 8 2 8 6}$ \\
\hline Complete & 0.9758 & 0.9756 & 0.7350 \\
\hline Ward & 0,9746 & 0.9677 & 0.4284 \\
\hline Single & 0.9789 & 0.9769 & 0.7584 \\
\hline WPGMA & $\mathbf{0 . 9 8 2 5}$ & $\mathbf{0 . 9 7 7 4}$ & 0.8254 \\
\hline
\end{tabular}

Küme sayısını belirlemek için uygun küme yöntemlerine göre hesaplanan CalinskiHarabasz ve Duda-Hart indeks değerleri Tablo 3'de verilmiştir.

Tablo 3:Calinski- Harabasz ve Duda-Hart İndeks Değerleri

\begin{tabular}{|c|c|c|c|c|c|c|}
\hline & \multicolumn{2}{|c|}{ WPGMA } & \multicolumn{2}{c|}{ WPGMA } & \multicolumn{2}{c|}{ Average } \\
\hline & \multicolumn{2}{|c|}{ Öklid } & \multicolumn{2}{c|}{ Gower } & \multicolumn{2}{c|}{ K-prototip $(\gamma=1)$} \\
\hline $\begin{array}{c}\text { Küme } \\
\text { Sayıs1 }\end{array}$ & $\begin{array}{c}\text { Calinski- } \\
\text { Harabasz }\end{array}$ & $\begin{array}{c}\text { Duda- } \\
\text { Hart }\end{array}$ & $\begin{array}{c}\text { Calinski- } \\
\text { Harabasz }\end{array}$ & $\begin{array}{c}\text { Duda- } \\
\text { Hart }\end{array}$ & $\begin{array}{c}\text { Calinski- } \\
\text { Harabasz }\end{array}$ & $\begin{array}{c}\text { Duda- } \\
\text { Hart }\end{array}$ \\
\hline 2 & 7338.60 & $\mathbf{0 . 9 6 5 8}$ & 7338.60 & 0.9658 & 2.05 & 0.9451 \\
\hline 3 & 3713.90 & 0.4560 & 3713.90 & 0.4433 & 3.33 & 0.1030. \\
\hline 4 & 2922.24 & 0.0847 & 2935.66 & 0.0847 & 2.21 & 0.0089 \\
\hline 5 & 9337.01 & 0.6414 & 9522.41 & 0.1030 & $\mathbf{2 2 9 5 . 9 6}$ & 0.9490 \\
\hline 6 & $\mathbf{9 7 7 9 . 2 2}$ & 0.6040 & $\mathbf{9 7 7 9 . 2 2}$ & 0.9478 & 1899.31 & $\mathbf{0 . 9 5 7 3}$ \\
\hline 7 & 9572.31 & 0.4377 & 8214.03 & $\mathbf{0 . 9 9 9 2}$ & 1622.40 & 0.4377 \\
\hline
\end{tabular}


Tablo 3'de görüldüğü gibi, üç uzaklık ölçümü kullanılarak yapılan uygun kümeleme yöntemlerine göre ortak küme sayısı 6 olarak bulunmuştur. $\mathrm{Bu}$ yöntemlere göre elde edilen dendogramlar Şekil 1, Şekil 2 ve Şekil 3'te gösterilmiştir.

Şekil 1'de Öklid uzaklığı kullanılarak WPGMA yöntemi ile elde edilen Türkiye'nin konut talebinde benzer özellik gösteren illerine ait kümeler aşağıdaki gibi belirlenmiştir.

1.Küme: Adana, Mersin, Kastamonu, Sinop, Bartın, Zonguldak, Hatay, İzmir, Antalya, Aydın, Muğla, Artvin, Giresun, Ordu, Rize, Trabzon, Samsun, Bursa, Kocaeli, Sakarya, Balıkesir, Çanakkale, Edirne, Kırklareli, Tekirdağ.

2.Küme: Yalova.

3.Küme: İstanbul.

4.Küme: Adıyaman, Kilis, Gaziantep.

5.Küme: Afyon, Kütahya, Manisa, Uşak, Karaman, Çankırı, Kayseri, Sivas, Yozgat, Kahramanmaraş, Osmaniye, Karabük, Burdur, Isparta, Denizli, Ağrı, Ardahan, Iğdır, Kars, Batman, Mardin, Siirt, Şırnak, Aksaray, Kırıkkale, Nevşehir, Niğde, Bingöl, Elazı̆̆ Malatya, Tunceli, Amasya, Çorum, Tokat, Gümüşhane, Bitlis, Hakkari, Muş, Van, Bilecik, Eskişehir, Bolu, Düzce, Ankara.

6.Küme: Bayburt, Erzincan, Erzurum, Diyarbakır, Şanlıurfa.

Şekil 1: Öklid Uzaklığı Kullanılarak WPGMA Yöntemi ile Elde Edilen Türkiye İlleri Dendogram 1

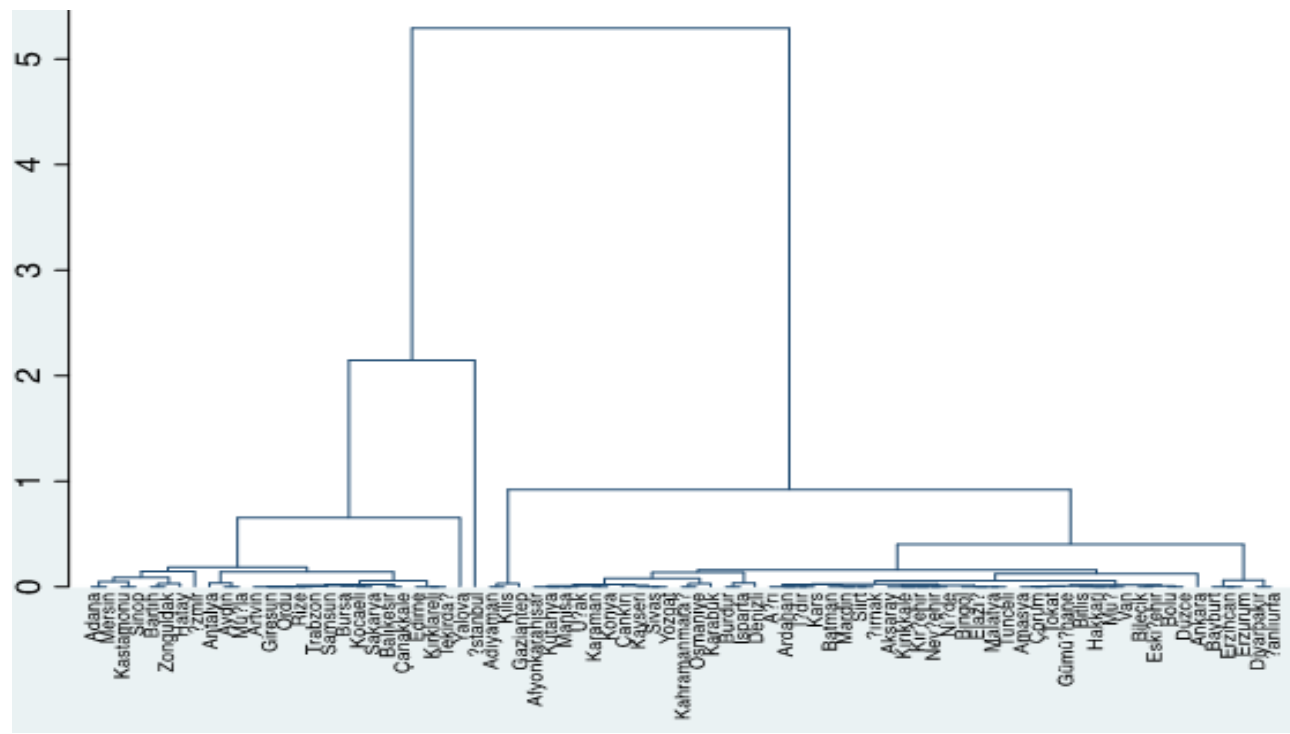


Şekil 2:Gower Uzaklığı Kullanılarak WPGMA Yöntemi ile Elde Edilen Türkiye İlleri Dendogram1

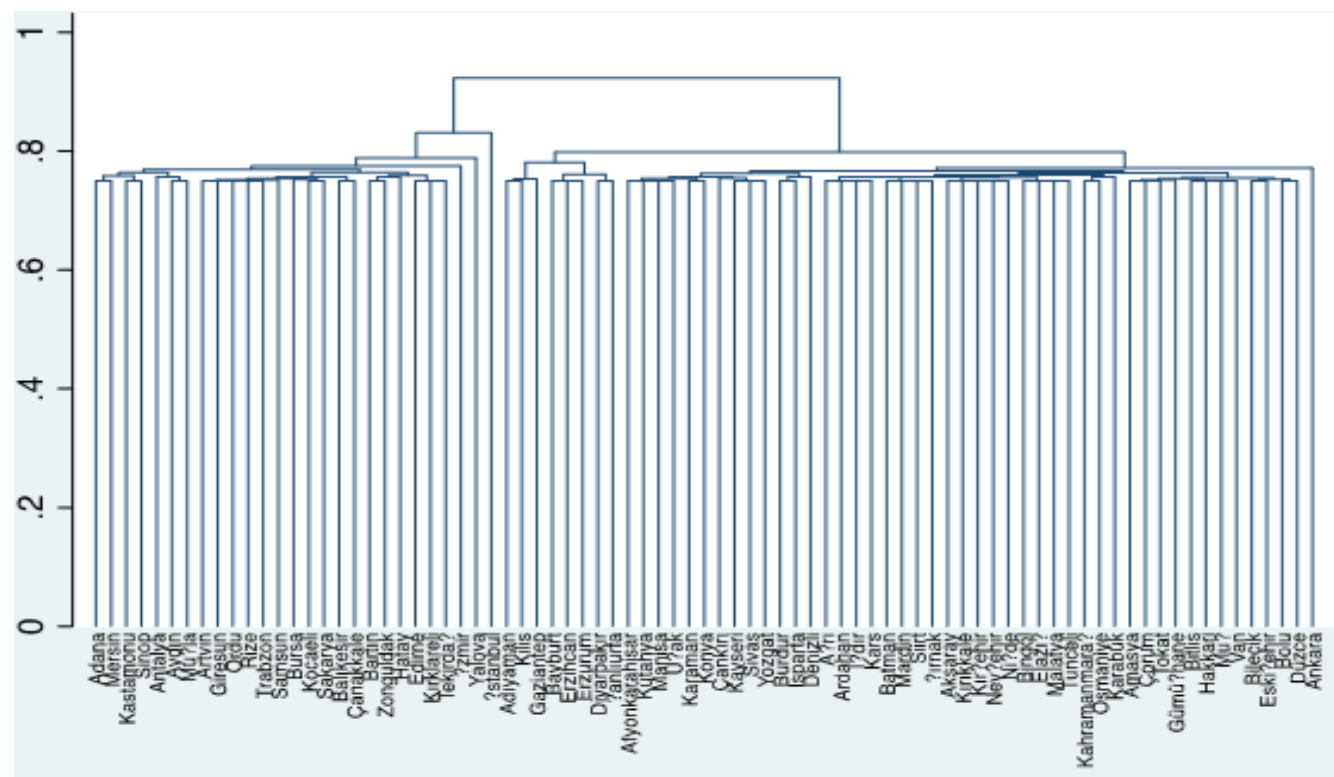

Şekil 2'de Gower uzaklığı kullanılarak WPGMA yöntemi ile elde edilen Türkiye'nin konut talebinde benzer özellik gösteren illerine ait kümeler aşağıdaki gibi belirlenmiştir.

1.Küme: Adana, Mersin, Kastamonu, Sinop, Antalya, Aydın, Muğla, Artvin, Giresun, Ordu, Rize, Trabzon, Samsun, Bursa, Kocaeli, Sakarya, Balıkesir, Çanakkale, Bartın, Zonguldak, Hatay, Edirne, Kırklareli, İzmir.

2.Küme: Yalova.

3.Küme: İstanbul.

4.Küme: Adıyaman, Kilis, Gaziantep.

5.Küme: Bayburt, Erzincan, Erzurum, Diyarbakır, Şanlıurfa.

6.Küme: Afyon, Kütahya, Manisa, Uşak, Karaman, Konya, Çankırı, Kayseri, Sivas, Yozgat, Burdur, Isparta, Denizli, Ağrı, Ardahan, Iğdır, Kars, Batman, Mardin, Siirt, Şırnak, Aksaray, Kırıkkale, Kırşehir, Nevşehir, Niğde, Bingöl, Elazı̆̆g, Malatya, Tunceli, Kahramanmaraş, Osmaniye, Karabük, Amasya, Çorum, Tokat, Gümüşhane, Bitlis, Hakkari, Muş, Van, Bilecik, Eskişehir, Bolu, Düzce, Ankara. 
Şekil 3: K- Prototip Uzaklığı Kullanılarak Ortalama Bağlantı Yöntemi ile Elde Edilen Türkiye İlleri Dendogramı

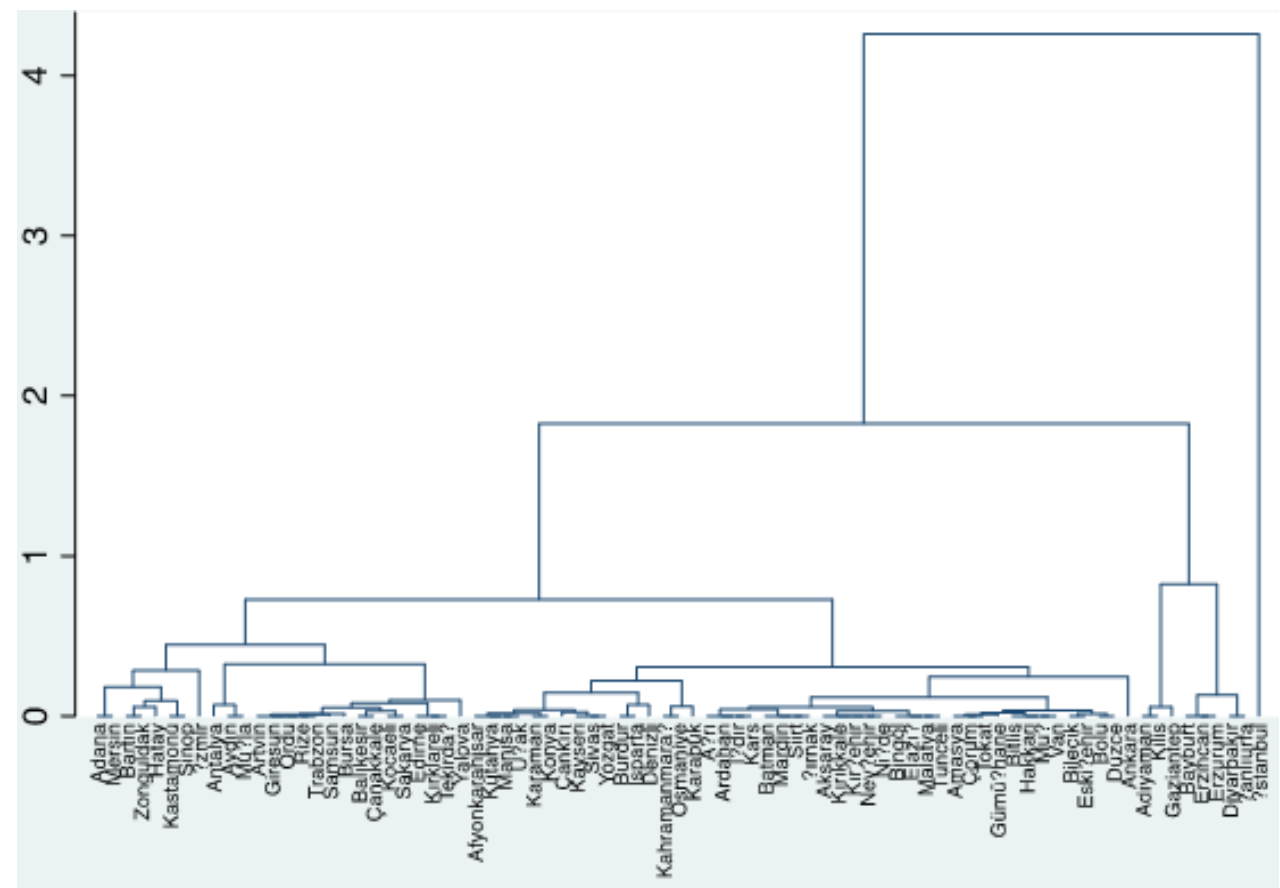

Şekil 3'ten de görüldüğü gibi K- prototip uzaklığı kullanılarak Ortalama bağlantı yöntemi ile elde edilen Türkiye'nin konut talebinde benzer özellik gösteren illerine ait kümeler aşağıdaki gibi belirlenmiştir.

1.Küme: Adana, Mersin, Kastamonu, Sinop, Bartın, Zonguldak, Hatay, İzmir.

2.Küme: Antalya, Aydın, Muğla, Artvin, Giresun, Ordu Rize, Trabzon, Samsun, Bursa, Kocaeli, Sakarya, Balıkesir, Çanakkale, Yalova, Edirne, Kırklareli, Tekirdağ.

3.Küme: Afyon, Kütahya, Manisa, Uşak, Karaman, Konya, Çankırı, Kayseri, Sivas, Yozgat, Kahramanmaraş, Osmaniye, Karabük, Burdur, Isparta, Denizli, Ağrı, Ardahan, Iğdır, Batman, Mardin, Siirt, Şırnak, Aksaray, Kırıkkale, Kırşehir, Nevşehir, Niğde, Elazı ̆̆, Malatya, Tunceli, Amasya, Çorum, Tokat, Gümüşhane, Bitlis, Hakkari, Muş, Van, Bilecik, Eskiş̧ehir, Bolu, Düzce, Ankara.

4.Küme: Adıyaman, Kilis, Gaziantep.

5.Küme: Erzincan, Erzurum, Diyarbakır.

6.Küme: İstanbul

Kümeleme sonuçlarının iyiliğini ya da geçerliliğini belirlemek için çeşitli istatistiksel indeksler geliştirilmiştir. Dunn, Silhouette ve Connectivity indeksleri bunlardan bazılarıdır. Dunn indeksi birleşik ve daha iyi ayrılmış kümeleri 
tanımlamak için önerilmiştir. Dunn indeks değeri daha büyük olan kümeleme, geçerli kümeleme olarak kabul edilmektedir. Silhouette katsayısı, birimlerin ne kadar iyi kümelendiğinin belirlenmesi veya kümelerin kararlılık yapısı için kullanılmaktadır. Silhouette istatistiği ise, $i$. birimin kendi kümesi içindeki diğer birimlerle farklılığını kendisine en yakın komşu kümedeki birimlerin farklılığı ile karşılaştırmaktadır. Hesaplanan istatistik değeri -1 ile +1 arasında olup +1 'e yakın olması durumunda $i$. birimin doğru sınıflandırıldığı yorumu yapılır. Bu istatistik değerlerinin ortalaması Ortalama Silhouette istatistiği adını almaktadır. Bir veri setindeki kümeleme yapısının 'uygun' olarak nitelendirilebilmesi için bu ortalama değerin 0,50 olması beklenmektedir. Ortalama Silhouette istatistiği değerinin en yüksek elde edildiği küme, analiz için en uygun küme olacaktır. Connectivity değeri, veri kümesindeki birimlerin en yakın komşularıyla ne derecede aynı kümeye yerleştirildiğine karşılık gelmektedir. Bu değer, 0 ile sonsuz aralığında değer alır ve minimum olmalıdır.

Tablo 4:Küme Geçerlilik İndeks Değerleri

\begin{tabular}{|c|c|c|c|}
\hline & WPGMA & WPGMA & Average \\
\hline & Öklid & Gower & K-prototip $(\gamma=1)$ \\
\hline Dunn & 0.1722 & $\mathbf{0 . 9 6 7 1}$ & 0.1903 \\
\hline Silhouette & $\mathbf{0 . 7 1}$ & 0.02 & 0.63 \\
\hline Connectivity & $\mathbf{1 4 . 3 7 3 0}$ & 119.9492 & 17.975 \\
\hline
\end{tabular}

Veri setine uygun uzaklık ölçümü ile kümeleme yöntemini belirlemek amaciyla küme geçerlilik (Dunn, Silhouette, Connectivity) indeks değerleri hesaplanmış ve Tablo 4'te verilmiştir.

Tablo 4'e bakıldığında, Dunn indeks değerine göre Gower uzaklığı kullanılarak yapılan WPGMA kümeleme yöntemi (0.9671) iyi sonuç verirken, Silhoutte (0.71) ve Connectivity (14.3730) indeks değerlerine göre uygun yöntem Öklid uzaklığı kullanılarak yapılan WPGMA kümeleme yöntemidir. Bu nedenle veri seti için uygun kümeleme yöntemi Öklid uzaklığı kullanılarak yapılan WPGMA kümeleme yöntemi olarak belirlenir.

\section{Sonuç ve Öneriler}

$\mathrm{Bu}$ çalışmada, uzaklık ölçümüne göre uygun kümeleme yöntemi belirlenerek Türkiye'nin konut talebinde benzer özellik gösteren illerini tespit etmek amaçlanmıştır. Bu doğrultuda, 2008-2015 yılları arasında Türkiye illerinin konut talebi ve konut talebini etkileyen ekonomik faktörleri ele alınarak panel veri seti oluşturulmuştur. Panel veri seti, Öklid, Gower ve K-prototip uzaklık ölçümleri kullanılarak toplamsal hiyerarşik kümeleme yöntemleri (Average, Complete, Ward, Single, WPGMA) ile kümelenmiştir. Cophenetic korelasyon katsayısı kullanılarak 
uzaklık ölçümlerine göre uygun kümeleme yöntemleri belirlenmiştir. Buna göre, Öklid ve Gower uzaklığ Average yöntemi uygun bulunmuştur. Belirlenen kümeleme yöntemlerinin Calinski-Harabasz ve Duda-Hart indeks değerleri hesaplanarak uygun küme sayısı 6 olarak elde edilmiştir. Kümeleme yöntemlerinin küme geçerlilik (Dunn, Silhouette, Connectivity) indeks değerlerine göre çalışmada kullanılan veri seti için en uygun kümeleme Öklid uzaklığının kullanıldığı WPGMA yöntemi olarak belirlenmiştir. Ampirik uygulama bölümünde yer alan Şekil 1'de görüldüğü gibi WPGMA yöntemine göre bir birimlik mesafede oluşan dendogram grafiğine göre Türkiye'nin konut talebinde benzer özellik gösteren iller altı küme olarak gruplanmıştır. Birinci kümedeki 25 ilin benzerliği, belirtilen yıllarda satışların daha çok tüketim amaçlı konut taleplerinden kaynaklandığı tahmin edilebilir. Mevsimlik işçilerin göç aldığı iller ortak özellik oluşturmaktadır. Yaz ve kış mevsimlerinde turizm açısından elverişli illerde bir aradadır. Bunun yanında, eğitim, iş sektörü, ticaret, endüstri, kültür ve sanat, tarihi yapı ve gelişmeler gibi birçok ortak özellik taşıyan iller bir aradadır. Konut talebinde ikinci ve üçüncü kümede yer alan Yalova ve İstanbul illeri tek başlarına bu kümelerde incelenmektedir. Yalova ilinin üretken tarım arazileri, masmavi denizi ve temiz plajları, geniş ormanlık alanları ile kaplı olması nedeniyle yaz aylarında nüfusu üç kat artmaktadır. Ayrıca şehrin 'Termal', olarak adlandırılan ve çok sayıda kaplıca barındıran bölgeleri nedeniyle konut talebinde tek başına bir kümede değerlendirilmektedir. İstanbul ilinin; sanayi, ulaşım, endüstri, eğitim ve teknik, politik, magazin, turizm, kültür ve sanat potansiyelleri yüksektir. Ayrıca buradaki konutlar özellikle ekonomik geliri yüksek olan tüketicileri ve yatırımcıları kapsamaktadır. Dolayısıyla Yalova ve İstanbul illerinin konut talebi, tüketim ve yatırım amaçlı hizmetlerden oluşmaktadır. Dördüncü kümede Adıyaman, Kilis ve Gaziantep illeri konut talebinde bir arada bulunmaktadır. $\mathrm{Bu}$ illerin konut talebinde ortak özellik göstermelerinin temel nedeni Suriye ve Irak gibi ülkelerden gelen göçmenlerin yoğun konut talebi ve ticari hayatta gayrimenkul teminatı kaynaklı bir yapının egemen olması şeklinde açıklanabilir ve bu illerinin konut talebi, yatırım amaçlı olduğu söylenebilir. Beşinci kümedeki 44 ilden; genellikle kışın soğuk geçen illerin konut taleplerindeki benzerliklerinin, yatırım amaçlı olduğunu göstermektedir. Bu ifade ilk olarak illerin ortak özelliği olan soğuk geçen havalarda insanların mecbur kalmadıkça taşınmayı tercih etmeyecekleri şeklinde desteklenebilir. Acenteler hedef kitlelerini doğru tanımlayıp bu mevsimde tüketim amacının aksine yatırım amaçlı konut talebinde bulunmasıyla acentelerin satış başarısını artıracaktır. Son olarak konut talebinde altıncı kümede Bayburt, Erzincan, Erzurum, Diyarbakır ve Şanlıurfa illeri yer almaktadır. Bu illerin konut taleplerinde ortak özellik göstermelerinin nedeni; ekonomik yapılarının tarım ve hayvancılığa dayanmasıdır. Ayrıca Gayri Safi Hasılaları, sanayi, ticari ve hizmet sektörleri, kaplıca ve kültür turizmleri, Rafting ve akarsu sporları ortak özellik göstermektedir. Sonuçta bu illerin konut taleplerindeki benzerliklerinin, yatırım amaçlı olduğu görülmektedir. 
Literatürde yapılan çalışmalara bakıldığında, genel olarak konut talebini etkileyen demografik ve ekonomik faktörler ele alınarak konut talebi üzerine model oluşturulmuş ve konut talebi tahmini yapılmıştır. Bu çalışmada da literatüre benzer olarak konut talebini etkileyen ekonomik faktörler ele alınmıştır. Ancak ele alınan faktörler ile Türkiye'nin konut talebinde benzer özellik gösteren illeri belirlenmeye çalışılmıştır. Böylece benzer illerde hangi amaçla konut talebinde bulunulduğu ortaya konulmaya çalışılmıştır.

Araştırmacılar konut sektörünün makro ve mikro ekonomik şartlardan çok etkilendiğini ileri sürmektedirler. Bununla birlikte konut sektörü ilgili şartlarda meydana gelecek değişikliklerin de en fazla hissedildiği iş kollarından birisidir. $\mathrm{Bu}$ nedenle araştırma uzmanları, konut talebinde 'duyarlılı̆̆ı' ve 'eğilimleri' anlamak için gerek küresel gerekse de ülkemize ait makroekonomik etkilerin analiz edilmesini önermektedirler.

\section{Kaynakça}

Akay, Ö. and Yüksel, G. (2018). Clustering the mixed panel dataset using Gower's Distance and k-prototypes algorithms. Communications in Statistics-Simulation and Computation, 47(10), 3031-3041.

Akay, Ö. and Yüksel, G. (2019). Hierarchical clustering of mixed variable panel

data based on new distance. Communications in Statistics-Simulation and Computation, 1-16.

Bajari, P. and Kahn, M. E. (2005). Estimating housing demand with an Application to explaining racial segregation in cities. Journal of business \& economic statistics, 23(1), 20-33.

Bourdieu, P. and Wacquant, J. D. (1992). An invitation to reflexive sociology. Chicago: Chicago UniversityPress.

Donaldson, C. and Gerard, K. (1998). Economics of health care financing (Rev. ed.). MacmillanPress Ltd.

Çelik, C. ve Kıral, G. (2018). Kümeleme yöntemiyle konut talebinin incelenmesi:

Türkiye il grupları üzerine bir uygulama. Çukurova Üniversitesi Sosyal Bilimler Enstitüsü Dergisi, 27(1), 123-138.

Çelik, C. ve Kıral, G. (2018). Yurtdışı Yerleşiklerin ve Dış Ülkelerin Konut Taleplerini İncelemede Panel Kümeleme Analizi: Türkiye İlleri Örneği, Çukurova Üniversitesi İktisadi ve İdari Bilimler Fakültesi Dergisi, 22(2), 305324.

Goodman, A. C. and Kawai, M. (1982). Permanent income, hedonic prices, and

Demand for housing: New evidence. Journal of Urban Economics, 12(2), 214-237. 
Ioannides, Y. M. and Zabel, J. E. (2003). Neighbourhood effects and housing demand. Journal of applied Econometrics, 18(5), 563-584.

Green, R. and Hendershott, P. H. (1996). Age, housing demand, and real house

prices. Regional Science and Urban Economics, 26(5), 465-480.

Quigley, J. M. (1976). Housing demand in the short run: An analysis of polytomous choice. In Explorations in Economic Research, 3(1),76-102.

Goodman, A. C. (1990). Demographics of individual housing demand. Regional

Science and Urban Economics, 20(1), 83-102.

Jud, G. D. and Frew, J. (1986). Real estate brokers, housing prices, and the demand for housing. Urban Studies, 23(1), 21-31.

Rapaport, C. (1997). Housing demand and community choice: an empirical analysis. Journal of Urban Economics, 42(2), 243-260.

Daşkıran, F. (2015). Denizli Kentinde Konut Talebine Etki Eden Faktörlerin Hedonik Fiyatlandırma Modeli ile Tahmin Edilmesi. Journal of International Social Research, 8(37).

Güriş, S., Çağlayan, E. and Ün, T. (2011). Estimating of Probability of Homeownership in Rural and Urban Areas: Logit, Probit and Gompit Model. European Journal of Social Sciences, 21(3), 405-411.

Gujarati, D. (2016). Örneklerle ekonometri. (N. Bolatoğlu. Çev.). Ankara: BB101 Yayınları.

Lu, H. and Huang, S. (2011). Clustering Panel Data. SIAM International Workshop on Data Mining held in conjunction with the 2011 SIAM International Conference on Data Mining. 1-10.

Zheng, B. and Li, S. (2014). Multivariable panel data cluster analysis and its application. Computer Modeling \& New Technologies, 18(1), 553-557. 